\title{
Bridging the Gap between Planning and Environmental Psychology: An application of sense of place for visioning of public policy
}

\author{
Masahiro Shirotsuki ${ }^{1}$, Satoshi Otsuki², Miho Sonoda ${ }^{3}$ \\ ${ }^{1}$ Ritsumeikan Global Innovation Research Organization, Ritsumeikan University, Kyoto Japan \\ ${ }^{2}$ General Education Centre, Kochi University, Kochi Japan \\ ${ }^{3}$ Department of Liberal Arts, Kagoshima Women's Junior College, Kagoshima Japan \\ castle@fc.ritsumei.ac.jp
}

\begin{abstract}
This paper aimed to explore a new methodology for vision making and sharing of a local municipality. The study explored using the residents' sense of place as a key element of the vision for the local town in order to ease the conflict or discomfort that can arise among diverse populations of merged municipalities. A method named Visioning with Sense of Place was developed for this study. Analyses indentified that the visioning process stimulated the participants to develop a broader sense of place with the new town.
\end{abstract}

Keywords: Municipal merger, vision, sense of place, correspondence analysis

eISSN 2514-751X @ 2017 The Authors. Published for AMER ABRA by e-International Publishing House, Ltd., UK.. This is an open access article under the CC BY-NC-ND license (http://creativecommons.org/licenses/by-ncnd/4.0/). Peer-review under responsibility of AMER (Association of Malaysian Environment-Behaviour Researchers), ABRA (Association of Behavioural Researchers on Asians) and cE-Bs (Centre for EnvironmentBehaviour Studies), Faculty of Architecture, Planning \& Surveying, Universiti Teknologi MARA, Malaysia.

https://doi.org/10.21834/aje-bs.v2i2.174 


\subsection{Introduction}

From 1999 to 2006, Japan experienced a large-scale municipality merger. This merger was enforced by the central government's strong policy initiatives, which included special subsidies during a limited period and punitive reduction of the local tax allocation to small local governments, based on the Act on Special Provisions of the Merger of Municipalities instituted in 1995. As a result of this movement, the total number of local municipalities (city, town, and village) dramatically decreased from 3,229 to 1,777 by April 2009. The expansion of the local governments' administrative areas led them to include socioculturally different populations with different values within the same territory. Consequently, conflicts over issues such as the location of a new governmental office, priorities of public works projects and naming of the new local municipality have emerged in 'administratively' consolidated populations across the nation. These conflicts have driven the municipalities to find balance in administrative management, which conversely means implementation of pork-barreling policies even though the municipality merger was promoted on the principles of efficiency and transparency in administration. What is the cause of the emotional conflict or discomfort? Ultimately, everyone wishes for his or her own place to be better than other places; this effect is regarded as psychological bonding with place.

Sharing the vision, which describes a picture of the future of the municipality in specific terms and regulates the direction of public policy, will help to remedy the emotional conflict or discomfort and allow for more efficient and transparent administration management. In this aspect, it is important to carefully consider the aspect of psychological relationships with place and reflect them in the visioning process of the municipalities.

\subsection{Why do the conflicts emerge?}

The conflicts between residents in the same local government derive mostly from (1) the merger process being conducted without sufficient preliminary explanation from the local government, (2) dissatisfaction with methods of resource allocation, and (3) gaps in values among populations.

From 1999 onward, Japan's central government strongly enforced the promotion of large-scale municipality mergers. Following this policy, the prefecture (that is, the higher administrative body of local municipalities) proposed 'ideal forms' of new municipalities and encouraged the establishment of a statutory council to prepare for the merger. Since local municipalities had been under strong pressure to proceed with the merger, consensus building among residents seemed less important, except in a few local municipalities with sufficient financial bases or strong public opposition. Also, resource allocation has been one of the residents' biggest concerns; more precisely, they were concerned about allocation of financial resources. There are two types of mergers: consolidation and absorption. In general, the former type applies to municipalities that have roughly equivalent populations and areas as their neighbours. In this type of merger, a conflict sometimes arises among the municipalities' residents, particularly when both groups try to decide the location of the 
new government office, which is frequently regarded as the symbolic centre of politics and economy. On the other hand, an absorption merger takes place in comparatively larger towns or cities that keep their legal personalities and incorporate small municipalities into their administrations. Both mergers share certain similarities, in that people who are living in the geographic and political centre have economic and emotional advantages, whereas those who live away from the centre feel disadvantaged or isolated. This, therefore, becomes the cause of conflict between people. We can see this example in many municipalities in Japan.

Finally, value gaps among the population may cause conflicts or discomfort. As many existing studies in environmental psychology have pointed out, people's 'place attachment' grows with the amount of time they have spent living in that place (Ahlbrandt, 1984: Kasarda, 1974: Taylor, 1996). This means that the longer they live in their own place or community, the stronger their attachment to the place; this place attachment makes them more sensitive to an intrusion by an outsider (Hanyu, 2008). Therefore, it is reasonable to suppose that groups of people who originate from different municipalities feel strong psychological bonds to their own municipalities and conversely feel a sense of discomfort or rivalry toward others.

We can easily determine the source of emotional conflicts between the populations of the merged local municipality. All of the conflicts are derived from residents' sense of place (attachment to their 'own' places), dissatisfaction with insufficient consensus building, a feeling of being at a disadvantage in the absorbed municipality, and a feeling of discomfort among the different groups of a population; all of these relate back to an individual's sense of place. Therefore, it is important for the local government resulting from the mergers to take into account how the residents have psychologically bonded with their place and how this bonding should be incorporated into the municipality's vision in order to build consensus among the population and remedy the conflicts.

\subsection{The lack of interdisciplinary exploration between planning and environmental psychology}

The importance of the interdisciplinary collaboration between planning and environmental psychology is poorly recognized at both the academic and policymaking levels. In general, 'literature on place attachment focuses on individual feelings and experiences and has not placed these bonds in the larger, sociopolitical context in which planners operate. Conversely, the community planning literature emphasises participation and empowerment, but overlooks emotional connections to place (Manzo \& Perkins, 2006)'. As this argument indicates, personal psychological relationships with place have been largely neglected in the domains of public policy and planning. Admittedly, we can find a few examples in which applied personal psychological relationship with place has been used as a key concept of planning in regard to 'regional identity'; creating a symbolic building or place in the town, identifying a landmark, or maintaining a historically important area are all examples of this practice. However, the objectives of these practices seem mainly to be (1) promotion of the 
town to the dwellers of urban areas for development of tourism or (2) compensation or remedy for a redevelopment project in which the original residents will be resettled or the original landscape will be changed. Planners implicitly recognize the importance of personal psychological bonding with place, as this bond is a potential driving force of residents' persistent opposition to developments; this opposition often manifests itself in the form of NIMBY (Not in My Backyard) or LULUs (Locally Unwanted Land Uses) protests. Because of these issues, the argument for consensus building or development of consensus-building techniques has been made in planning domains worldwide. However, the focus on psychological issues in planning is limited to how its construct affects negatively impacts efficient and rational policy implementation processes. Theoretical importance of the psychological relationship with place remains outside of planning theory.

Over the past few decades, psychologists (especially environmental psychologists) have made great contributions to the understanding of people's psychological relationships with place. The statement, 'Place-identities are systems of defining and expressing the personal identity of the individual (Proshansky, 1978)', is a typical example of how environmental psychologists view the role of psychological bonding with place. 'Research in environmental psychology mainly examined place attachment to the development of self and community identity (Ujang, 2010). Their main interest has been how the person- place relationship is constructed and affects the development of personal identity, not how these relationships impact public policy or have a practical purpose in our daily lives. Some previous studies have shown that personal psychological bonding with place impacts our behaviours. Vaske and Kobrin et al. (2001) found that place identity was more strongly associated with environmentally responsible behaviour (Vaske \& Kobrin, 2001). Kyle et al. (2004) found that place identity was a significant positive moderator of fee support of U.S. recreational sites in California (Kyle, Mowen \& Tarrant, 2004). However, despite the studies conducted in this field, planners remain oblivious to this issue. This is the lack of interdisciplinary collaboration and in differences of perspective across disciplines (Manzo \& Perkins, 2006)'.

\subsection{Vision Making Among Merged Municipalities}

Ohnan Town in Shimane Prefecture (located in the southern centre part of the prefecture) in Japan was selected as the case study area. Ohnan Town was established by a municipal merger in 2004, which consolidated the former Iwami Town, Mizuho Town, and Hasumi Village. These areas are separated by a massive chain of mountains, and each municipality had separate living, economical, and cultural environments. In this aspect, it is easily assumed that people living in these three regions had different values and sense of place that had to be merged in Ohnan Town. 


\subsection{Vision as the model of the future}

The word 'vision' has not been applied formally to administrative legal language in Japan. In the Revised Local Autonomy Law, there is a reference to a relevant concept, which reads as follows: 'The city, town and village shall, with the approval of their respective assembly, establish basic policies to accomplish the comprehensive and planned administration within their areas, and perform the affairs in line with such established policies' (Article 2.4). In this statement, municipalities are requested to form a basic direction for the policy in order to achieve policy implementation that is both effective and efficient. In other words, the law has implicitly assumed the importance of the vision. According to Ruppert, the vision of a municipality is defined as 'a holistic outlook unfettered by feasibilities and practicalities, beginning on a blank canvas to scratch the shape of tomorrow's society (2001)'. Similarly, Ache (2000) said, 'A vision is a model of the future for a region and its inhabitants, it is a strategy for the development of the spatial and settlement structures, it is a test routine for everyday decisions and actions'. It should be added that 'it [vision] is far more a concept that is developed and discussed in regional cooperation and where finally a regional consensus is found. Therefore, it has to be easily understood, comprehensible and clear (ibid.)'.

\subsection{Methodology Design: Visioning with Sense of Place (VSOP) method}

For this study, a total of 10 participants were selected who lived in former Iwami Town (4 people), Mizuho Town ( 3 people), and Hasumi Village (3 people). The sample consisted of 8 male and 2 female participants. The age distribution ranged from 31 to 53 years, with a mean of 38.5 years.

For the purpose of this study, we designed the VSOP method, which is intended to encourage participants to speculate about their individual sense of place and to reflect their sense of place onto the vision of Ohnan Town. As mentioned, this study employed the sense of place scale, which was developed by Jorgensen and Stedman (Jorgensen \& Stedman 2001). However, the scales that they developed were originally designed for a study of a lakeshore in northern Wisconsin, U.S.A., using a questionnaire survey. Each item for evaluating the sense of scale includes more than one part and mentions the specific place name. Taking into consideration workshop-style methodology and ability to understand the meaning of the 'sense of place' concept, we simplified each concept and carefully explained the concept to the participants, with necessary re-explanation in the process (Table 1). 
Table 1: Scale items of Sense of Place

Item Item description

Place attachment

Place identity

Place dependence
" $\mathrm{X}$ " is my favourite place to be

Everything about " $X$ " is a reflection of me

For doing the things that I enjoy most, no other place can compare to "X"

The following approach was employed in this study. In step 1, the facilitator asked all participants to fill in the name of place individually in the small slips, without limitation to their original town or village, in which they feel the sense of place. In step 2, the facilitator asked all participants to stick all the slips on a large display board so that every participant could see them (10 minutes). In step 3, all participants were asked to stand as a resident of 'new town' (Ohnan Town) and, through open-ended discussion (15 minutes), choose the slips that they considered symbolic elements of the town. In step 4, the facilitator assisted all participants in grouping the presented slips based on physical and social commonality and asked them to give a name to each group (10 minutes). In step 5, the grouped elements were circulated among all participants and checked for appropriateness (10 minutes). In step 6, all participants were asked to consider the groups that could be shared by residents of Ohnan Town and choose the candidate groups by voting (no limitation on the number of groups) in 15 minutes. In step 7, all participants were asked to draft a single statement on a desirable future of the town. Actual time required for this process was around 60 minutes without logistical working time.

Table 2: VSOP testing process

\begin{tabular}{lll}
\hline Step & Phase & Didactics \\
\hline Step 1 & $\begin{array}{l}\text { Self- } \\
\text { thinking }\end{array}$ & $\begin{array}{l}\text { (a) Request each participant to write, on a small slip of paper, } \\
\text { the elements that help evoke a sense of place. }\end{array}$ \\
Step 2 & $\begin{array}{l}\text { Idea } \\
\text { presentation }\end{array}$ & $\begin{array}{l}\text { (b) Ask all the participants to put their slips on the display } \\
\text { board so that they are visible to all. }\end{array}$ \\
Step 3 & $\begin{array}{l}\text { Idea } \\
\text { selecting }\end{array}$ & $\begin{array}{l}\text { (c) Ask each participant to choose the elements that he/she } \\
\text { considers symbolic of the new town. }\end{array}$ \\
Step 4 & Summarising & $\begin{array}{l}\text { (d) Implement the Delphi Technique and assist the participants } \\
\text { in grouping the common elements. }\end{array}$ \\
Step 5 & Confirming & $\begin{array}{l}\text { (e) Circulate the grouped elements among the participants } \\
\text { to reach a consensus. }\end{array}$ \\
Step 6 & Sharing & (f) Request the participants to vote for the element groups
\end{tabular}


that could be shared by the residents of the new town.

$\begin{array}{lll}\text { Step } 7 & \text { Visioning } & \text { (g) Have each participant draft a statement on the desirable }\end{array}$ future of the town.

\subsection{Preliminary Analysis}

The corresponding analysis was employed to analyse a distribution pattern of participants' sense of place with their original town. The following data were collected from all participants in step 1. Thus, the result gained from these data represents a nearly unbiased pattern of the participants' sense of place to their own town or village. The total number of selected elements was 27 . The standard deviation (SD) for abscissa is 0.865 while that for ordinate is 0.884 . The distributed pattern of participants' sense of place, shown in Figure 1, demonstrates some interesting trends among the units of municipalities. At first, it is obvious that the participants recognised that the objects with sense of place are the things that should be original to their own town and village, not part of the new town.

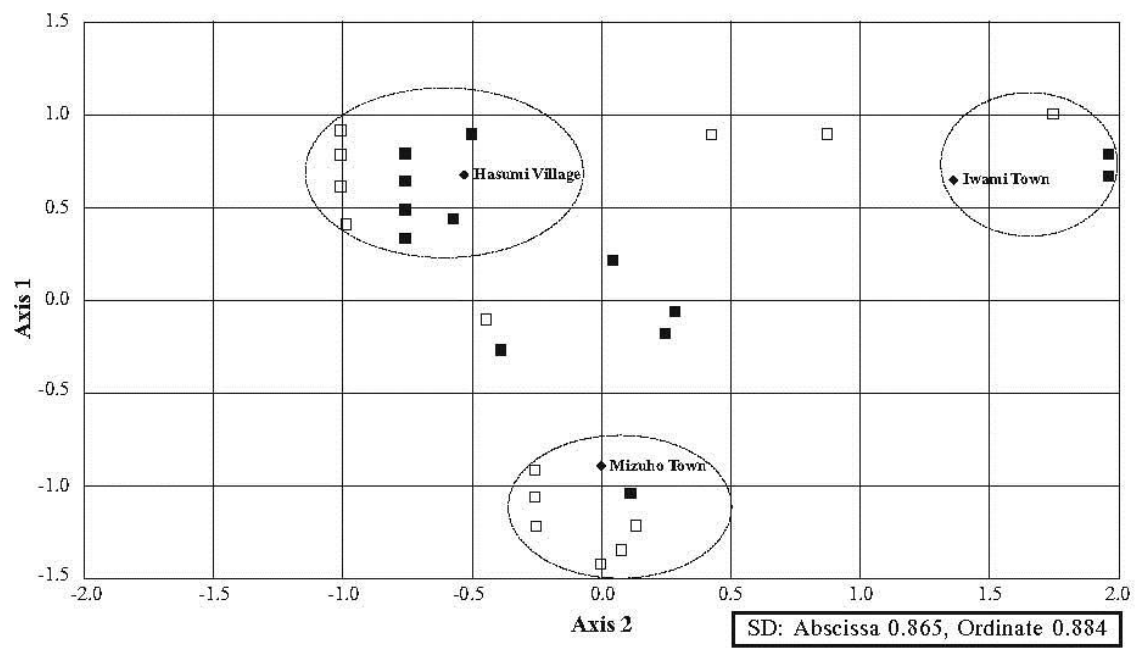

Figure 1: Participants' sense of place pattern by original residential area (step 1)

As this figure shows, a number of unique objects were selected as the objects of their sense of place, except for the example of Mizuho Town (e.g. a specific place such as a shrine, temple or station). Second, there were only three objects, which are plotted at the centre of the figure, that are assumed to be potential elements that all participants from separate towns and village are able to share as common objects of the new town (e.g. nature, river and rural landscape). These observations may suggest that residents from each former town and village have formed their sense of place according to their own place; 
more broadly, they self-recognised as a resident of their own town or village, not as a resident of the new town, despite more than four years having passed since the merger.

\subsection{Transformation of the sense of place to the new town}

Figure 2 shows the distributed pattern of participants' sense of place with Ohnan Town at step 3 of the test. The total number of selected elements was 28. SD for abscissa is 0.599 , while that for ordinate is 0.804 . This figure explains that the participants' sense of place with the new town was still related to their unique objects in their own town and village. There were some objects that were assumed as common objects of the new town (enclosed in a rectangle); however, all objects are common objects in Ohnan Town.

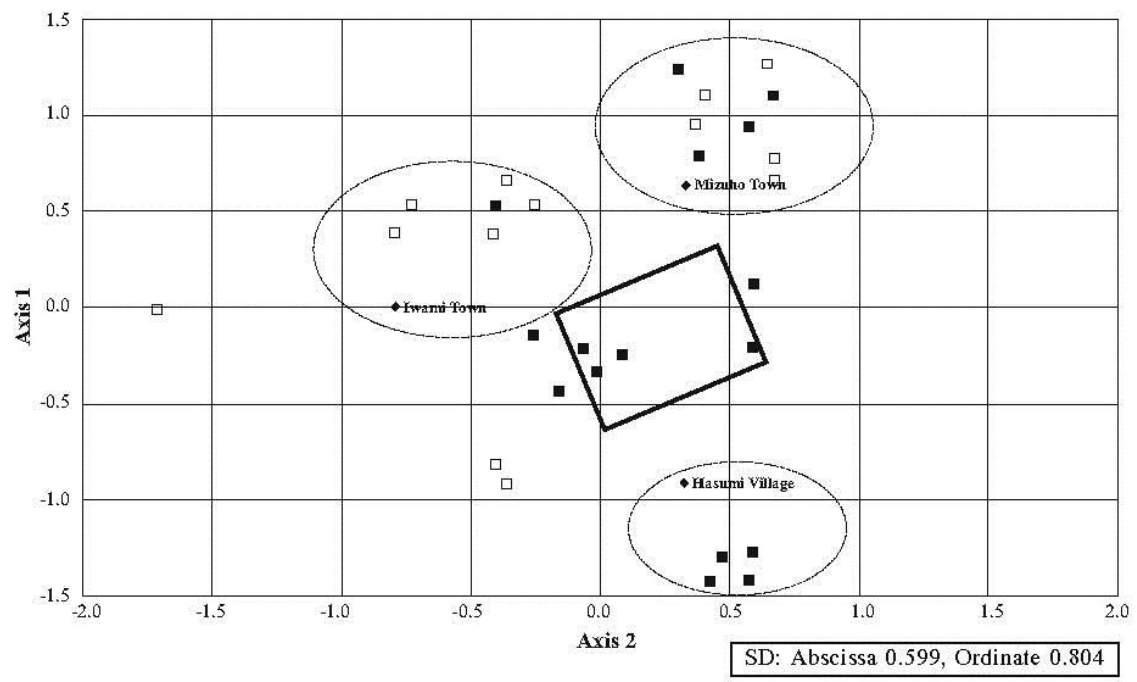

Figure 2: Participants' sense of place pattern to Ohnan Town (step 3)

Figure 3 shows a transformation of the participants' sense of place with the new town at the point of step 6 . SD reduced remarkably from the previous figure; abscissa is 0.288 , while that for ordinate is 0.602 . The number of elements selected by the participants dramatically decreased from 28 to 15 .

Moreover, the number of elements, which are assumed as the common objects, dramatically increased from step 3. Furthermore, it can be observed that unique objects of each town and village, initially shown only around the municipality dot on the figure, appear at the centre of the figure. This implies the participants obtained a greater sense of place in terms of spatial and conscious ranges through experiencing the series of steps in this test, even though the selected four unique elements are unique objects in each former town and village. 


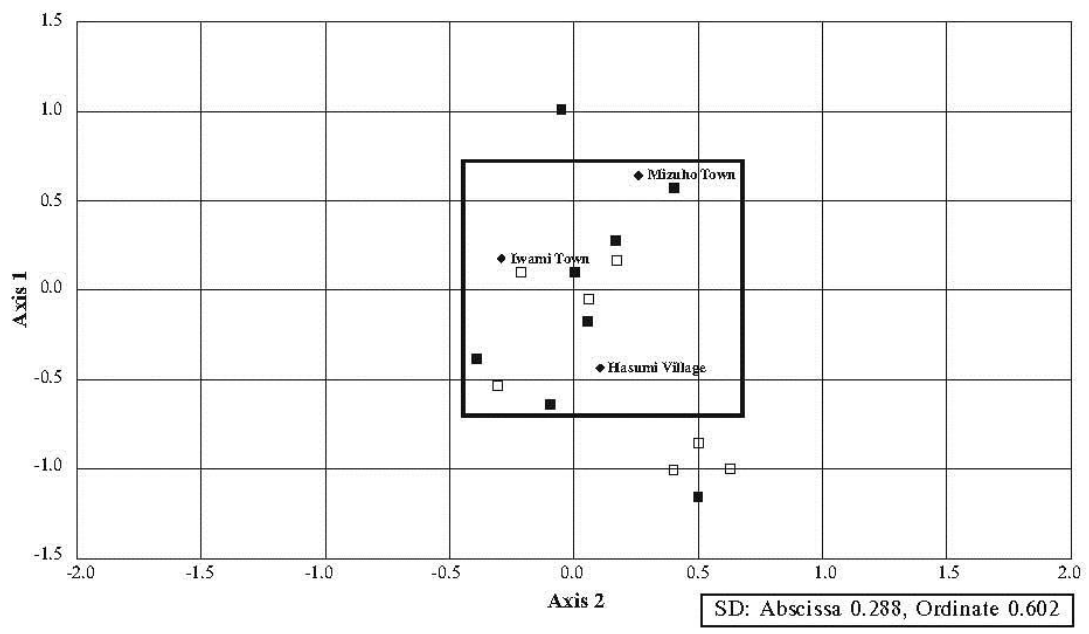

Figure 3: Participants' sense of place pattern to Ohnan Town (step 6)

\subsection{Feedback from nonparticipants}

The next argument concerns designing a vision for the new town based on the extracted 'sense of place' elements in the previous process. The facilitator asked all participants to discuss all the elements among themselves and group them according to their physical and sociocultural characteristics via the Delphi method (step 4). As a result, the participants finally grouped the elements into three groups: nature, traditional event, and humanness. Then, in step 7, the facilitator asked participants to draft their town's future vision with a single sentence in line with the grouped items. The vision that they created was 'Heartwarming town with plentiful nature and tradition', despite the fact that the official vision of the town is 'Energetic town with heart-warming, plenty of nature and dream'.

To get feedback on the drafted vision from nonparticipants living in Ohnan Town, a small-scale interview study was conducted in the Mizuho area (the centre of Ohnan) on 26 March 2008. In total, 54 samples were collected with semi-structured interviews. The sample was 19 percent male and 81 percent female. The age distribution ranged from 14 to 83 years, with a mean of 60.5 years). The interview survey was conducted through the following procedure by three well-trained interviewers. First, interviewers presented the vision drafted by the VSOP method with information about the grouped elements, which were created by the participants, on an A4-size paper. Then, respondents were asked to look through the information carefully within one minute. Finally, interviewers asked respondents to complete the questionnaire by four-level evaluation.

Table 3 shows the respondents' acceptance of the drafted vision; 98 percent of them evaluated the vision drafted by the participants as being agreeable as the vision of the 
newtown. This result provides us with a high degree of certainty regarding the appropriateness of the vision drafted by the participants, and, more accurately, by the general public, even though the sample used in this study was limited in terms of sample precision of the population.

Table 3: Evaluation of the vision by nonparticipants

\begin{tabular}{lcc}
\hline Scales & Number & Percentage \\
\hline Strongly agree & 31 & $62 \%$ \\
Agree to an extent & 18 & $36 \%$ \\
Disagree to an extent & 1 & $2 \%$ \\
Strongly disagree & 0 & $0 \%$ \\
\hline
\end{tabular}

\subsection{Discussion \& Conclusion}

A lack of understanding exists with regard to the importance of the environmental psychological aspect in the visioning process of public policy. Urban and community planners sometimes pay slight attention to the psychological factors involved in solving political conflicts in development projects; however, understanding this aspect has not been applied as a principle of the planning theory. The planning rationality and efficiency have been the only interests of the planners. Thus, planners have completely failed to take into account the importance of the psychological construct presented here, which is most likely to affect our daily well-being or quality of life by means of public policy. We focused on the concept of sense of place in this study and selected Japanese municipality merger as the case study. We wanted to examine the faultiness of its policy and intended to propose a new planning methodology for solving conflicting issues in the planning field.

The result of our experiment clearly shows, first, that the residents of Ohnan Town still have a strong sense of place with their own original town or village, despite more than 4 years having passed from the time of the merger. This result supports the existence of potential conflicts among the residents and implies the possibility of insufficient policymaking and implementation following a municipality merger. Second, we discovered that the vision drafted by the participants used their sense of place in the visioning process, which had an effective impact on transforming their sense of place to the new town. As we observed in the series of analyses of this study, the participants' sense-of-place objects were summarized on a step-by-step basis, and they finally obtained a wider sense of place, even when the elements originated from a different town or village. Third, the results made clear that it is possible to form a vision of public policy with consensus, through an 
operational application of residents' sense of place. Nonparticipants evaluated the vision that was drafted by the participants as preferable for the new town. This finding indicates that participation of residents in the visioning process is a realistic way of creating a vision for the local public policy.

However, this study does have some limitations. First, the size and accuracy of the samples in this study are limited. The participants in the test had to be carefully selected in terms of demographic attributes of the town. However, it also should be noted here that there were complex difficulties in the criteria given in this town. As mentioned above, Ohnan Town is a one of the most depopulating municipalities in Shimane Prefecture. Furthermore, a chain of mountains geographically divides each area. Hence, we should not deny the possibility that potential participants would have strong public-policy interests if we recruited equally from each area based only on their own voluntary will. In this sense, the manner in which this study was employed might be practical to some extent. Second, the visioning method employed participants' sense of place in the process and encouraged the participants to gain a wider sense of place to the new town. It is not yet clear whether sense of place is the only sufficient condition for creating a preferable vision of the town; we realize there may be an effect of the VSOP method, which allows participants to share close relationships and mutual understanding. Finally, it is also not clear whether the acceptance of the newly drafted vision by the nonparticipating residents of the town derived from a kind of sympathy for the selected words or the fact that their 'relatives' drafted the vision. We need further exploration of these points.

This study does provide an initial endeavour to bridge environmental psychology and planning. The facts extracted from this study provide important implications. Conflicts between residents following a municipality merger most likely stem from a difference in the residents' sense of place. As analysis in this paper has shown, most people are more likely to have a sense of place with their 'own' place, even if time has passed since the merger. However, these conflicts can be solved by encouraging people to participate in the visioning process or, more broadly, in the policymaking process by utilizing their sense of place in some form, because the most probable cause of the conflicts is the existence of diverse stakes that are derived from our sense of place. In this study, we focused on the emotional conflict and its possible remedy after merging of municipalities in Japan. The methodology developed and employed here provides a broader possibility of application into wide-range planning phases and spatial ranges.

\section{Acknowledgement}

This study was conducted as part of the HDP project, funded by Ritsumeikan University and supported by Ohnan Town Government in Shimane Prefecture. The views expressed, together with the responsibility for all errors and omissions, are solely of the authors. 


\section{References}

Ache, P. (2000).Vision and creativity-challenge for city regions.Futures, 32,435-449.

Ahlbrandt, R.S. (1984). Neighborhoods, People and Community.New York, Plenum.

Hanyu, K. (2008). Environmental Psychology. Science.

Jorgensen, B.S. \& Stedman, R.C. (2001). Sense of place as an attitude: lakeshore owners' attitudes toward their properties. Journal of Environmental Psychology, 21, 233-248.

Jorgensen, B.S. \& Stedman, R.C.(2006). A comparative analysis of predictors of sense of place dimensions: attachment to, dependence on, and identification with lakeshore properties. Journal of Environmental Management, 79, 316-327.

Kasarda, J.D.\& Janowitz, M. (1974). Community attachment in mass society. American Sociological Review, 39, 328-339.

Kyle, G.T., Mowen, A.J. \& Tarrant, M. (2004).Linking place preferences with place meaning: an examination of the relationship between place motivation and place attachment. Journal of Environmental Psychology, 24, 439-454.

Manzo, L.C. (2005). For better or worse: exploring multiple dimensions of place meaning. Journal of Environmental Psychology, 25, 67-86.

Manzo, L.C. \& Perkins, D.D. (2006). Finding common ground: the importance of place attachment to community participation in planning. Journal of Planning Literature, 20, 335-350.

Manzo, L.C. (2003). Beyond house and haven: toward a revisioning of emotional relationships with places. Journal of Environmental Psychology, 23, 47-61.

Proshansky, H.M., Fabian, A.K. \& Kaminoff, R. (1983).Place-identity: physical world socialization of the self. Journal of Environmental Psychology, 3, 57-83.

Proshansky, H.M. (1978). The city and self-identity, Environment and Behavior, 10, 147-170.

Ruppert, E.S. (2001). Re-visioning the City. Book reviews, Political Geography, 20, 113-134.

Taylor, R.B. (1996). Neighbourhood responses to disorder and local attachments: the systemic model of attachment, social disorganization, and neighbourhood use value. Sociological Forum, 11, 41-74.

Ujang, N. (2010).Place attachment and continuity of urban place identity, Asian Journal of Environment-Behaviour Studies, 1(2), 61-76.

Vaske, J.J. \& Kobrin, K.C. (2001). Place attachment and environmentally responsible behaviour. Journal of Environmental Education, 32, 16-21. 